FEDERAL RESERVE BANK OF SAN FRANCISCO

WORKING PAPER SERIES

\title{
The Effect of Extended Unemployment Insurance Benefits: Evidence from the 2012-2013 Phase-Out
}

\author{
Henry S. Farber \\ Princeton University \\ Jesse Rothstein \\ UC Berkeley \\ Robert G. Valletta \\ Federal Reserve Bank of San Francisco
}

January 2015

Working Paper 2015-03

http://www.frbsf.org/economic-research/publications/working-papers/wp2015-03.pdf

The views in this paper are solely the responsibility of the authors and should not be interpreted as reflecting the views of the Federal Reserve Bank of San Francisco or the Board of Governors of the Federal Reserve System. 
Version: January 15, 2015

\author{
The Effect of Extended Unemployment Insurance Benefits: \\ Evidence from the 2012-2013 Phase-Out* \\ Henry S. Farber \\ Princeton University \\ Jesse Rothstein \\ U.C. Berkeley \\ Robert G. Valletta \\ FRB San Francisco
}

\begin{abstract}
Unemployment Insurance benefit durations were extended during the Great Recession, reaching 99 weeks for most recipients. The extensions were rolled back and eventually terminated by the end of 2013. Using matched CPS data from 2008-2014, we estimate the effect of extended benefits on unemployment exits separately during the earlier period of benefit expansion and the later period of rollback. In both periods, we find little or no effect on job-finding but a reduction in labor force exits due to benefit availability. We estimate that the rollbacks reduced the labor force participation rate by about 0.1 percentage point in early 2014.
\end{abstract}

*Farber: Princeton University, Industrial Relations Section, Firestone Library, Princeton, NJ 08544, farber@princeton.edu. Rothstein: University of California, Berkeley, 2607 Hearst Avenue \#7320, Berkeley, CA 94720, rothstein@berkeley.edu. Valletta: Federal Reserve Bank of San Francisco, 101 Market St., San Francisco, CA 94105, rob.valletta@sf.frb.org. The views expressed in this paper are solely those of the authors and should not be attributed to the Federal Reserve Bank of San Francisco or the Federal Reserve System. This paper was prepared for the annual meeting of the American Economic Association, Boston MA, January 2015 and will be published in the American Economic Review, May 2015. 
The duration of U.S. Unemployment Insurance (UI) benefits was expanded to an unprecedented degree in the Great Recession, reaching a maximum of 99 weeks in many states by 2010. These expansions were then rolled back in 2012 and 2013. Since January 2014, no state has had UI benefits available beyond the normal duration (26 weeks in most states).

Unemployment insurance extensions may raise measured unemployment by reducing the incentive for recipients to find jobs quickly and by bolstering the incentive to engage in and report active job search. But the magnitudes of these effects are uncertain and may vary with economic conditions. In earlier work, we examined the effects of the 2008-2011 UI expansions, relying on cross-state and temporal variation in UI durations (Rothstein 2011; Farber and Valletta 2015). We found that benefit extensions slightly reduced the exit rate from unemployment, largely through increased labor force attachment rather than reduced job finding. ${ }^{1}$ These estimates may be affected by the historically weak labor market conditions around the Great Recession, however, and may not generalize to changes in UI durations under more favorable labor market conditions.

In this study, we update our earlier analyses to incorporate the phase-out of benefit extensions in 2012 and 2013. Figure 1 contains plots of median weeks of available UI, quarterly since 2007, along with a measure of labor market slack, the ratio of unemployment to job openings. ${ }^{2}$ This figure shows the run-up of UI availability in the Great Recession, from the basic 26 weeks early in 2008 to the maximum of 99 weeks in late 2009, followed by a decline beginning in early 2012. The benefit extensions came during a period of sharply increasing slack, but by the time of the rollbacks the labor market was substantially tighter. It is plausible that UI extensions could have larger effects on job finding in a tighter labor market (Kroft and Notowidigdo 2011).

We estimate models for the likelihood that an unemployed individual exits employment, using two different empirical specifications designed to isolate variation in UI durations produced by policy changes (as distinct from changes in labor demand conditions). We

\footnotetext{
${ }^{1}$ Our past and current analyses focus on worker search behavior. Other recent work examines the labor market effects of potential employer responses to UI extensions (Hagedorn et al. 2013).

${ }^{2}$ Weeks of available UI are measured monthly by state. We average this across months within quarters.
} 
Figure 1: Weeks of UI Available and Unemployed/Vacancies, Quarterly, 2007-2014Q2

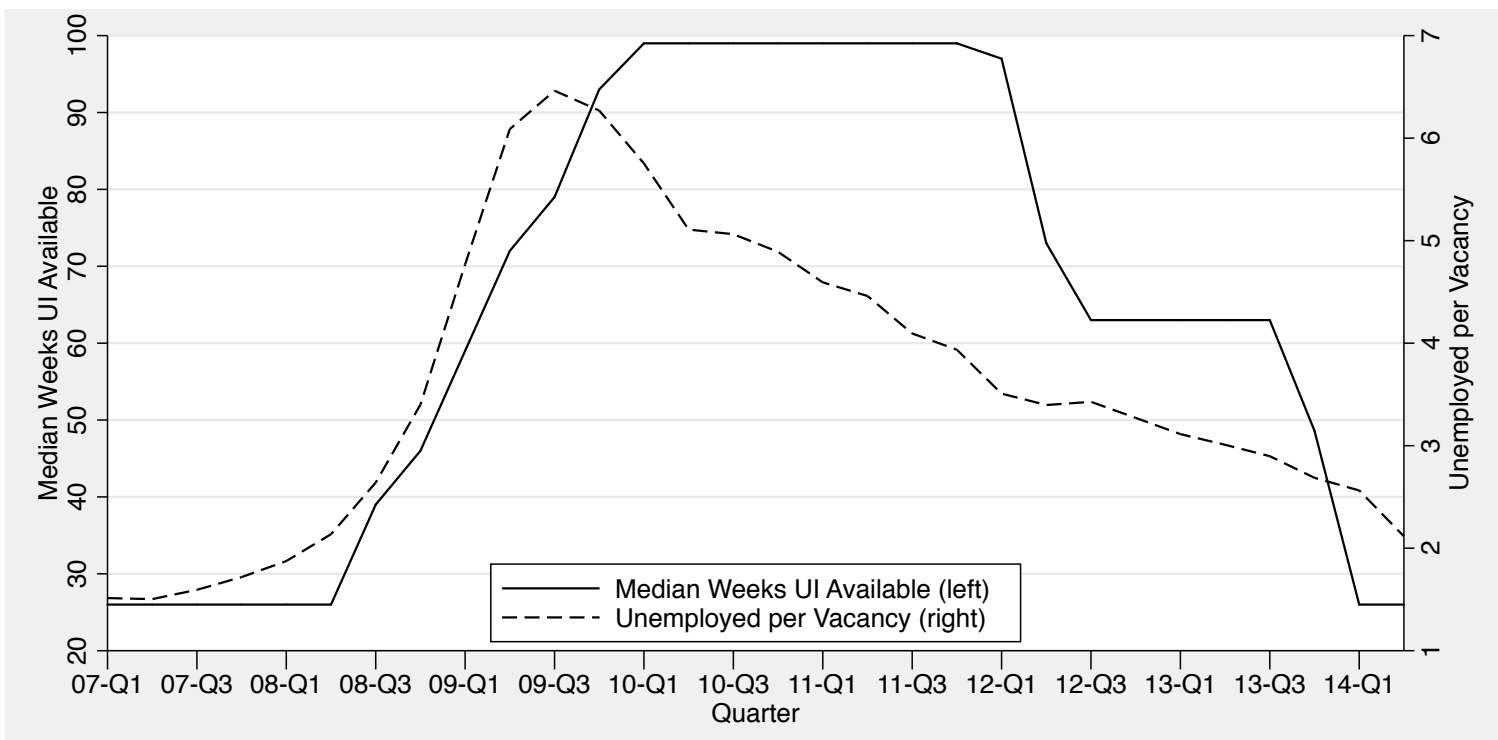

Note: UI weeks available is median across states, weighting states by the number of UI-eligible unemployed (authors' tabulations of weighted CPS microdata). Unemployed per vacancy computed from BLS tabulations of CPS and JOLTS data (seasonally adjusted).

estimate separate effects for 2008-2011, when UI durations were expanding or stable, and for 2012-June 2014, when they were contracting. We use a competing risks framework to model separate effects of UI extensions on exit to employment (job finding) and on exit from the labor force. Large effects on job finding would suggest important economic efficiency costs of UI extensions. By contrast, effects on labor force attachment have little or no implication for economic efficiency (Card, Chetty, and Weber 2007).

\section{The Expansion and Reduction of UI Benefit Durations, 2008-14}

The rapid decline in UI durations in Figure 1 reflects the automatic and legislated rollback of two programs that provided for extra benefits during the recession. These are the temporary Emergency Unemployment Compensation (EUC) program and the permanently authorized Extended Benefits (EB) program.

EUC was a federally-funded program, introduced and expanded in several steps beginning in July 2008. It provided for as many as 53 weeks of benefits through four separate "tiers," some of which were activated for all states and some of which were conditioned on high state 
unemployment rates. The program expired at the end of 2013, causing a reduction in median weeks of available UI from 63 to 26 (Figure 1).

EB provides for 13 or 20 additional weeks of benefits in states with high unemployment rates, following exhaustion of regular and emergency benefits. ${ }^{3}$ Most states became eligible for EB in early 2009. A provision in the EB rules restricts benefits to states with unemployment rates higher than they were three years prior. The rule became binding in early 2012, and by August 2012 no state was paying EB. ${ }^{4}$ This contributed to the first step down in Figure 1, as median weeks of benefits fell from 99 weeks in 2011Q4 to 63 weeks in 2012Q3.

EUC and EB complemented regular state benefits. These are typically 26 weeks, so the maximum duration of benefits during the period we study was 99 weeks (26 weeks regular benefits, 53 weeks EUC, 20 weeks EB). ${ }^{5}$ A few states cut regular benefit durations to less than 26 weeks in 2011 or later.

Our initial analysis exploits changes in benefit durations coming from changes in EUC rules, from the phase-out of EUC and EB, and from decisions by some states to cut regular benefits. We also present estimates that focus on variation arising directly from the phase-out of EB in 2012 and the termination of EUC at the end of 2013.

\section{Sample Definition and Data Issues}

We use Current Population Survey (CPS) microdata from January 2008 to August 2014 for individuals ages 18-69. We restrict our analyses to respondents who are unemployed and report job loss as the reason, and hence are potentially eligible for UI. ${ }^{6}$ Given our focus on

\footnotetext{
${ }^{3}$ State participation is optional. However, the federal government bore 100 percent of the cost of EB from 2009 through mid 2013, so state participation was high during the period of interest here.

${ }^{4}$ New York and Alaska briefly resumed EB payments later in 2012. No state paid EB benefits after April 2013.

${ }^{5}$ Some states had 63 weeks of EUC in early 2012, but this was conditional on not offering EB benefits, so the maximum duration never exceeded 99 weeks.

${ }^{6}$ Due to potential reporting errors and incomplete take-up rates for UI benefits, this is an imperfect means of identifying UI eligibility. See Rothstein (2011) and Farber and Valletta (2015) for further discussion.
} 
the effect of extended benefits, and because most new spells of unemployment end before extended benefits could be an important factor, we restrict attention to individuals who have been unemployed for at least 3 full months.

We use the reported duration of unemployment, together with state-level maximum benefit durations, to assign UI availability to individuals. We assume that job losers are eligible for the full duration of benefits and that each draws benefits continuously from the date of job loss until benefit expiration or exit from unemployment.

We use the panel structure of the CPS to identify exits from unemployment. Each sampled address (housing unit) is interviewed for 4 consecutive months, left alone for 8 months, then reinterviewed for another 4 months. This sample structure allows us to match unemployed individuals within households to month-ahead labor market outcomes for three consecutive months during each 4 -month rotation. ${ }^{7}$

One key concern with regard to use of the matched data is the likelihood of spurious transitions due to mismeasurement of labor force status (see, for example, Abowd and Zellner 1985). To address this concern, we follow the recoding approach developed in our earlier work. For unemployed individuals in month one who report a transition out of unemployment in month two (to employment or non-participation) and a return to unemployment in month three, we recode the month two status as unemployed. We retain and use the resulting observations created by the recode (with associated variables such as reason for unemployment and duration imputed based on their month one values). Imposing this adjustment to observed transitions requires three consecutive matched months of data and hence restriction to respondents in the first two of each set of four consecutive CPS interviews. As such, although we use CPS data through August 2014, our last measured exit hazards are for June 2014.

Our matched CPS sample covers January 2008 through June 2014 and contains 56,491 monthly observations on 37,059 spells of unemployment for eligible workers out of work three

\footnotetext{
${ }^{7}$ Failures to match occur primarily when a household moves to a new housing unit between interviews (less than five percent of cases). To ensure valid matches of individuals across months, we dropped a small number of observations for which reported age, gender, race, or educational attainment is not consistent across months (e.g., age changes by more than 1 year).
} 
Figure 2: Monthly Exit Rates from Unemployment, 2007-2014Q2 (seasonally adjusted)

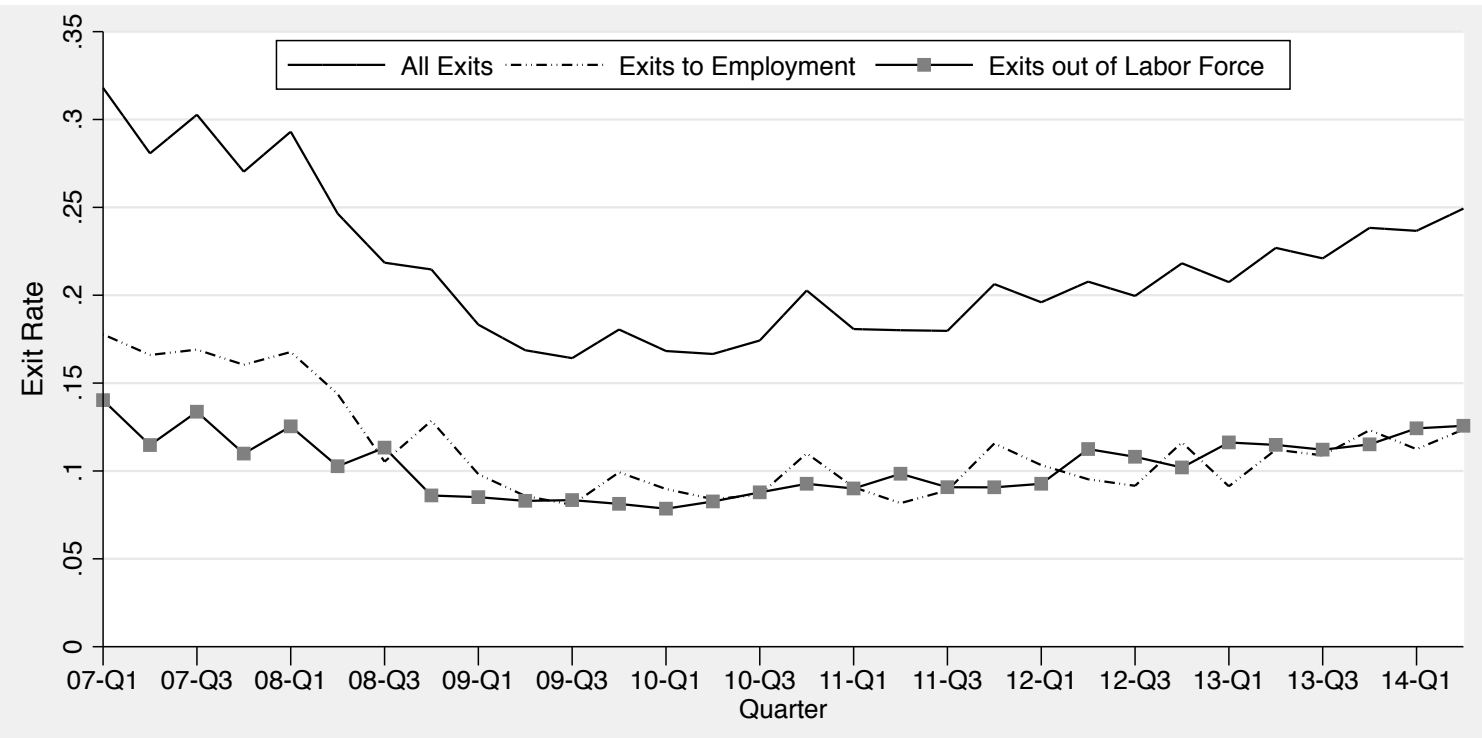

Note: Quarterly averages of monthly exit hazards, computed from weighted analysis sample of UI-eligible individuals unemployed for at least three full months.

months or more and aged 18-69. To compare our estimates across periods of extended benefit expansion and contraction, we split this sample in two: 2008-2011 and 2012-2014m6. In the earlier period, we use 24,735 spells of unemployment, of which 15.4 percent are observed to end in exit to employment and 13.4 percent are observed to end in exit from the labor force. In the later period, we use 12,324 spells, of which 16.4 percent are observed to end in exit to employment and 16.4 percent are observed to end in exit from the labor force.

\section{The Effects of Extended Benefits on Exits from Unemployment}

Figure 2 contains plots of seasonally adjusted monthly exit rates from unemployment (averaged by quarter) for the spells in our analysis sample. We show series for all exits, for exits to employment, and for exits out of the labor force. Total exits and exits to employment fell sharply in 2008 as the recession deepened. Both reemployment and labor force exit rates have risen gradually since the recession ended in mid-2009. There is no visible change in the rates of increase as extended benefits were phased out in 2012 and 2013.

Our primary estimates of the effects of UI durations come from a simple logistic discrete- 
choice model of exit from unemployment. The model is specified by assuming a spell ends in a given month $t$ if an unobserved latent variable for spell $i$ in state $s$ and month $t\left(y_{i s t}^{*}\right)$ is positive. This latent variable is modeled as

$$
y_{i s t}^{*}=X_{i s t} \beta+Z_{s t} \lambda+U I_{i s t} \delta+\omega_{s}+\psi_{t}+\epsilon_{i s t},
$$

where $X_{i s t}$ is a vector of individual variables, $Z_{s t}$ is a vector of time-varying state labor market variables, $\omega_{s}$ and $\psi_{t}$ are vectors of state and date (month-year) effects respectively, $\beta$ and $\lambda$ are vectors of coefficients, and $\epsilon_{i s t}$ is an error term with a logistic distribution. $U I_{i s t}$ (with coefficient $\delta$ ) is an indicator that equals one if individual $i$, identified as unemployed in state $s$ and month $t-1$, will have been unemployed in month $t$ (the potential transition month) for fewer weeks than the number of weeks of UI benefits available. ${ }^{8}$ We estimate the parameters specified in this relationship using a logit model of the observed monthly spell outcomes (exit or continuation). To examine the separate effects of $U I_{i s t}$ on exit to employment and exit out of the labor force, we use a competing risks version of this model. We assume that the two types of exit are independent events and treat each realized event as censoring the time until the other type of exit occurs.

The estimated model includes in the $X$ vector a set of standard personal characteristics that are systematically related to labor market outcomes: 4 education categories, 6 age categories (decade indicators covering the included ages 18-69), indicators for female, married, female*married, race/ethnicity, and indicators for 13 broad industry categories. In order to account for state labor market conditions over time $\left(Z_{s t}\right)$, the model includes a cubic in the monthly seasonally adjusted state unemployment rate and a cubic in the 3-month annualized growth rate in seasonally adjusted log non-farm payroll employment. To allow for a flexible baseline hazard and to account for the effects of normal UI benefits, the model also includes a set of indicators for months 4, 5, and 6 of unemployment and single indicators for months

\footnotetext{
${ }^{8}$ This specification follows Farber and Valletta (2015). Their models include an additional indicator for being in the final month of UI benefits. Inclusion of that variable does not affect our results. Rothstein (2011) takes a somewhat different approach to modeling extended UI effects but obtains results consistent with those presented here.
} 
Table 1: Estimated Average Marginal Effects on Probability of Exit from Unemployment Specification $1 \quad$ Specification 2

\begin{tabular}{c|c|c||c} 
Model & $2008-2011$ & $2012-2014 \mathrm{~m} 6$ & $2012-2014 \mathrm{~m} 6$ \\
\hline (1) Single Risk & -0.035 & -0.026 & 0.008 \\
& $(0.008)$ & $(0.011)$ & $(0.013)$ \\
\hline \hline (2) Exit to Emp & -0.001 & -0.002 & 0.004 \\
& $(0.007)$ & $(0.009)$ & $(0.009)$ \\
\hline (3) Exit from LF & -0.031 & -0.021 & 0.004 \\
& $(0.005)$ & $(0.008)$ & $(0.008)$
\end{tabular}

Columns 1 and 2 present the average marginal effect on the exit probability of an indicator for availability of UI benefits (a transformation of $\hat{\delta}$ ). Column 3 presents the average marginal effect of an indicator for the loss of benefits (a transformation of $\hat{\theta}$ ), controlling for an indicator for simulated benefit eligibility in the pre-expiration period. See text for a list of other controls included in the models and for spell counts.

7-9, months 10-12, and months 13 and beyond (6 categories in total). ${ }^{9}$ We also include a complete set of state and date (year-month) indicators $\left(\omega_{s}\right.$ and $\left.\psi_{t}\right)$ in the model.

The first two columns of Table 1 contain estimated marginal effects of UI availability on the probability of exit from unemployment. We present three estimates for each of our two time periods (2008-2011 and 2012-2014m6): One for all exits from unemployment, one for exit to employment, and one for labor force exit. The estimates for the single risk model (row 1) imply that the availability of UI benefits to an unemployed worker has a significant negative effect on the probability of exit from unemployment. The estimated effect is about 3.5 percentage points in 2008-2011 and 2.7 percentage points in 2012-2014. With an average monthly exit hazard around 20\% (figure 2), these imply that the availability of extended benefits reduced the monthly exit rate from unemployment by about 15 percent.

Consistent with our earlier work, the estimates for the competing risks of exit to employment and exit from the labor force (rows 2 and 3 of the table respectively) imply that the UI effect on overall exits is primarily driven by the participation margin rather than the employment margin. We find very small, statistically insignificant effects on exit to employ-

\footnotetext{
${ }^{9}$ Given the detailed controls for unemployment duration included in the model, our estimated effects of UI availability primarily reflect variation in extended benefits (EUC and EB). However, the estimated effects also reflect in part reductions of regular UI durations below 26 weeks in 8 states since 2011.
} 
ment in both periods. However, available UI benefits do have statistically and economically significant negative effects on labor force (LF) exit. The effect is 3.1 percentage points in 2008-2011 and 2.1 percentage points in 2012-2014. With an average rate of labor force exit of about 10 percentage points (figure 2), these estimates imply that the availability of extended benefits reduced the rate of labor force exit by those eligible for extended UI benefits by 20 to 30 percent. We cannot reject equality of coefficients across the two periods in any of our three models.

Column 3 contains results from an alternative specification that identifies the effect of UI availability only from variation due to the phase-out of EUC and EB. Specifically, we identify duration ranges that were covered by EUC and EB in each state prior to each program's disappearance, and we examine how unemployment exit rates for individuals in those ranges change following the relevant program's disappearance.

To implement this, we define four new variables: post $E U C_{t}$ and post $E B_{s t}$, indicators for observations after the end of EUC and EB benefits, respectively, in state $s$, and EUCrange $e_{i s t}$ and EBrange ${ }_{i s t}$, indicators for observations with unemployment durations that were covered by EUC and EB in the last month in which the relevant program was available in the state. These vary across states based on the specific benefit durations. For example, California offers 26 weeks of regular benefits. Before the state lost EB eligibility in April 2012, it had 53 weeks of EUC and 20 weeks of EB benefits. Thus, in California EBrange ist $_{\text {is }}$ an indicator for an unemployment duration between 80 and 99 weeks. Subsequent EUC changes reduced California's EUC benefits to 37 weeks before it expired in December 2013, so in California EUCrange ist $_{\text {is }}$ an indicator for a duration between 27 and 63 weeks. Across states, individuals with EUCrange ist $=1$ would have received EUC benefits in the months before December 2013 but not afterward, while those with EBrange $_{i s t}=1$ would have received EB benefits in the months before their state's EB program phased out but not afterward.

We model the latent propensity to exit unemployment as

$$
\begin{aligned}
y_{i s t}^{*}= & X_{i s t} \beta+Z_{s t} \lambda+\gamma \text { postEB } B_{s t}+\pi_{E U C} E_{U C \text { Crange }_{i s t}}+\pi_{E B} \text { EBrange }_{i s t} \\
& +\theta \max \left(\text { EUCrange }_{i s t} * \text { postEUC } C_{t}, \text { EBrange }_{i s t} * \text { postEB } B_{s t}\right)+\omega_{s}+\psi_{t}+\mu_{i s t} .
\end{aligned}
$$


The coefficient of interest is $\theta$, capturing the change in the exit hazard at the relevant durations for those who have lost benefits due to elimination of the EB or EUC programs in a state. ${ }^{10}$ We expect $\theta$ to have the opposite $\operatorname{sign}$ from $\delta$, as it reflects the effect of not having access to UI benefits. ${ }^{11}$ Point estimates are much smaller in magnitude here than in Columns 1-2. We can never reject zero effects and, based on the implied confidence intervals, we can rule out quantitatively large effects on either exit margin.

\section{$4 \quad$ Final Comments}

We draw two primary conclusions from our analysis. First, there is no evidence that the effects of UI were larger under the tighter labor market conditions since 2012. This is consistent with the finding from Farber and Valletta (2015) of little difference in UI effects between the Great Recession and the less severe recession of the early 2000s. Second, the primary effects of extended UI are on labor force attachment rather than job finding. From this perspective, the phasing out of extended and emergency benefits reduced the unemployment rate mainly by moving people out of the labor force rather than by increasing the job-finding rate.

One implication is that the expiration of extended UI benefits may have put downward pressure on the labor force participation rate in 2012 and after. However, our estimates indicate that this effect is small. Even in 2014, less than $15 \%$ of the unemployed (and well under $1 \%$ of the population) would have received UI benefits but for the rollback, and our estimates imply that the availability of benefits reduced their likelihood of exiting the labor force each month by under 2.5 percentage points (or around 10\%). A rough calculation that combines these figures and cumulates over the time since the benefits were rolled back indicates that the extended UI rollbacks reduced the labor force participation rate in mid2014 by at most 0.1 percentage point, and likely less. ${ }^{12}$ We conclude that the phaseout of

\footnotetext{
${ }^{10}$ The main effect of postEUC $C_{t}$ is absorbed by the calendar month controls.

${ }^{11}$ In a linear probability model for $U I_{i s t}$ that includes the other controls, the coefficient on the benefit loss interaction is -0.58 (S.E. 0.01).

${ }^{12}$ See the appendix for details.
} 
extended UI is not important for explaining why labor force participation has remained low during the recovery.

A stronger implication of our results is that the UI extensions have not had large moral hazard effects on recipients' job-finding rates, either during the worst period of the Great Recession or during the subsequent recovery. Our point estimates suggest a near-zero effect in each period, and confidence intervals are small enough to rule out any quantitatively important effect. This suggests that the UI extensions around the Great Recession had very limited impacts on labor market efficiency.

\section{References}

Abowd, John M., and Arnold Zellner. 1985. "Estimating Gross Labor-Force Flows." Journal of Business and Economic Statistics 3 (3): 254-83.

Card, David, Raj Chetty, and Andrea Weber. 2007. "The Spike at Benefit Exhaustion: Leaving the Unemployment System or Starting a New Job?" American Economic Review, Papers and Proceedings 97: 113-118.

Farber, Henry S., and Robert G. Valletta. 2015. "Do Extended Unemployment Benefits Lengthen Unemployment Spells? Evidence from Recent Cycles in the U.S. Labor Market." Journal of Human Resources (in press).

Hagedorn, Marcus, Fatih Karahan, Iourii Manovskii, and Kurt Mitman. 2013. "Unemployment Benefits and Unemployment in the Great Recession: The Role of Macro Effects.” NBER Working Paper No. 19499, October.

Kroft, Kory, and Matthew J. Notowidigdo. 2011. "Should Unemployment Insurance Vary with the Local Unemployment Rate? Theory and Evidence." NBER Working Paper No. 17173, June.

Rothstein, Jesse. 2011. "Unemployment Insurance and Job Search in the Great Recession." Brookings Papers on Economic Activity (Fall): 143-196. 


\section{Appendix: Calculation of Labor Force Participation Effect}

Our calculation of the effect of the roll-back of UI benefits on the labor force participation rate has four parts. First, we estimate the average treatment effect of UI availability on the monthly hazard for exiting the labor force. Second, we compute the number of treated individuals in each month - those who had exhausted their UI benefits but would have still received benefits had benefit durations not been rolled back. Third, we multiply these two to obtain the effect of the UI benefit rollbacks on monthly unemployment to nonparticipation flows. Finally, we cumulate this flow across the period since the rollbacks began to estimate the total effect of the rollbacks on the number of non-participants at each point in 20122014m6. We discuss each step in turn.

Our estimates of the average treatment effect of UI availability are based on the specification from Table 1, Column 2, Row 3. We use the coefficients from this specification to estimate the marginal effect of UI availability on the labor force exit probability, then average this over all UI recipients (with greater than 3 months unemployment duration) each month to obtain a monthly average treatment effect. This allows the treatment effect to vary as the characteristics of the long-term unemployed population and the baseline exit hazard change over time. It ranges from about 1.8 to 2.5 percentage points, on a base exit hazard that ranges from 20 to $25 \%$ per month from 2012 forward (see Figure 2).

To estimate the number of people directly affected by the rollback of UI in each month, we identify the benefit duration in each state in January 2012 and in each month $t$ thereafter. We identify those directly affected as job-losers in our CPS analysis sample in month $t$ with unemployment durations in between the month- $t$ maximum benefit duration and the January 2012 maximum benefit duration. These individuals would have received UI benefits in month $t$ had benefits been kept at their January 2012 level.

The Bureau of Labor Statistics adjusts the raw tabulations from the CPS file, for example by seasonally adjusting them, to create its official series. We adjust our estimates of the number of directly affected individuals to make them consistent with the BLS series: We use our sample to estimate the share of job losers with unemployment durations of 27 weeks or more who are directly affected by duration reductions, then multiply this by the official 
series for the number of job losers unemployed for 27 weeks or more.

The third step of our calculation is to estimate the effect of the UI rollback on monthly flows from unemployment to nonparticipation. This is simply the product of the number of affected individuals, from step two, with the average treatment effect, from step one. We estimate that the UI rollbacks induced around 8,000 individuals to exit the labor force per month in 2013, rising to about 30,000 per month in the first half of 2014 .

The final step in the calculation is to cumulate these flows to obtain the effect of the UI rollbacks on the stock of non-participants. The simplest approach is to simply sum the flows. This yields a reduction in the labor force (and the labor force participation rate, respectively) of 121,000 (0.05 percentage point) in November 2013 and 321,000 (0.13 p.p.) in June 2014. But this presumes that the rollback-induced exiters would all have stayed in the labor force forever in the counterfactual world where UI benefit durations remained at their peak. A more realistic assumption is that they would have exited at the average rate seen among long-term unemployed job losers, with a monthly hazard around $12 \%$. When we adjust for this, we estimate that the UI rollbacks reduced the labor force by just over half as much as implied by the first calculation, with an effect on the labor force participation rate of 0.03 p.p. in November 2013 and 0.07 p.p. in June 2014. Taking all of the estimates together, a 0.10 percentage point effect on the rate is a reasonable upper-bound estimate. 